\title{
オブザーバを用いた最適レギュレータの評価
}

\author{
高浪薰・伊藤正美 \\ 名古屋大学工学部 名古屋市千種区不老町 \\ (昭和 47 年 3 月 11 日 受付)
}

\section{On the Performance Index of an Optimal Regulator Using an Observer}

\author{
Kaoru TAKanami and Masami Ito \\ (Faculty of Engineering, Nagoya University, Nagoya) \\ (Received March 11, 1972)
}

\begin{abstract}
In optimal regulator problems an increase in the value of the performance index (P.I.) is in general encountered when a Luenberger observer is employed to construct the estimates of the state-variables which are not available by direct measurement.

In this paper $\exp D t(D:$ the coefficient matrix of observer) is studied with respect to the increase in P.I. and it is shown that for the case where $n \geq 3$ ( $n$ : dimension of the system), in almost all cases the increase in P.I. becomes arbitrarily large when the real parts of the observer eigenvalues become highly negative. Moreover it is discussed for what quadratic performance index the control law using the estimates of the state-variables is optimal. In this case, a sufficient condition is derived, and the relation between the weighting coefficients in the performance index and the eigenvalues of the observer is discussed.
\end{abstract}

\section{1. 緒事}

最適レギュレータ問題に执いて測定できない状態变 数を Luenberger オブザーバ1,2)を用いて推定し，そ の推定量を用いてレギュレータを構成するとき，一般 にすべての状態変数が測定できる場合に比して評価の 增分が生じる. J.J. Bongiorno \& D.C. Youla はこの 評価に怙ける増分の定式化を行ない，オブザーバの次 数が系の次数と同じ場合にはオブザーバの固有值の実 部を負の無限遠に近づけるとき，評価（J）に和ける 增分 $(\Delta J)$ は任意に小さくすることが可能であると 結論した ${ }^{3)}$. しかし，その後の論文で誤りを指摘し， $\Delta J$ は任意に小さくすることができないと訂正しだ). この理由は, $\exp D t(D:$ オブザーバの安定な係数行 列) のノルムを $c \exp (-\mu t)$ ( $c$ は $D$ 之無関係な定 数, $-\mu<0$ は $D$ の固有値のらちで一番大きな実部の 值よりも大）で括さえたことにめり，その後cはDの 固有值飞依存して和り，Dの固有值の絶対值が大きく なるとcる大きくなるといら事実に気付いたためであ る. これによって，オブザーバの次数が系の次数に同 じ，あるいはそれ以下の場合でもともに $n \geqq 3(n:$ 系 の次数）に执いては，オブザーバの固有值を負の無限 遠に近づけるとき，ほとんどの場合 $\Delta J$ は無限大とな ることがわかった。このことは，速かに状態を推定す ることが最適レギュレータの評価の意味で必ずしも最 適でないことを意味しているが，これはレギュレータ に括将る 2 次形式評価と速い状態推定という本質的に 異なる尺度を混同しているからにほかならない。

さて，これに対する対策として，これまで次の 2 と 扣りの方法が研究されている。

（i）オブザーバを用いると，一般に，システムの 評価は初期状態に依存するので実用的に意味のある初 期状態の範囲を定めて，その範囲内での增加分 $\Delta J$ の 最大值を最小にするように，オブザーバの固有值を決 定する方法 ${ }^{3}$

（ii）初期状態の統計的な性質を既知として，增加 
分の期待値を最小にする最適なオブザーバを設計する 方法 ${ }^{5}$

しかし、これらのすべての議論は，はじめに理想的 な仮定（すべての状態が直接測定できるという）に拉 いて設定された 2 次形式評価Jを絶対なるのとして， それに基づいてオブザーバの固有值をきめていこうと するものである.もともと，理想的なレギュレータに 和ける評価 $J$ とオブザーバの固有值とは無関係なもの であるし，また，最適レギュレータと括ける 2 次形式

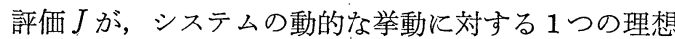
的な規範であることを考光ると，Jにあるり固執する ことは無意味であると思われる。それよりもむしろ， 状態变数が直接測定できない場合, オブザーバを用い たレギュレータ系がぞのような動的挙動をするのか， 定性的な性質を明確汇把握して和くことのほうが重要 と思われる，そこで，本稿ではオブザーバを考慮した 新しい 2 次形式評価を考光，オブザーバによる状態変 数の推定量を用いたレギュレータ系がその 2 次形式評 価の意味でいかなる最適な系であるかを，評価に括け る重みとオブザーバの固有值との関係に特いて考察す る.

な特，本稿は，1 入力1出力系を扱い，まず，2，で オブザーバの構成法の簡単なまとめを行ない， 3 ，で $\Delta J$ とオブザーバの固有值との関係を, 交献 (4) と は異なる方法によって示す，そしてさらに，これらを 基礎にして，4，で，オブザーバの固有值と新評価関 数との関係を論じ，数值例を与える。

\section{1 入为 1 出力亲のオブザーバの構成法}

まず，対象とする系は完全可制御，かつ完全可観測 であるとする。したがって一般性を失うことなく，系 は可観測標準形式で表わすことができる。

$$
\begin{aligned}
& \dot{\boldsymbol{x}}=F \boldsymbol{x}+g u \\
& y=h^{\prime} \boldsymbol{x} \text { “'”転置を示す }
\end{aligned}
$$

ここで, $\boldsymbol{x}$ は $n$ 次元状態ベクトル, $u$ はスカラー入力, $y$ はスカラー出力である.

ただし，

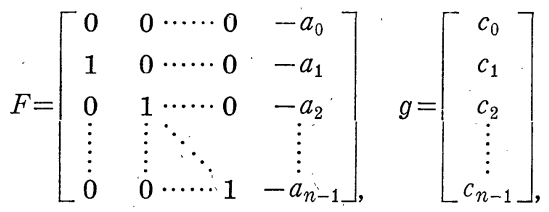

$$
\begin{aligned}
& h=\left[\begin{array}{c}
0 \\
\vdots \\
\vdots \\
\vdots \\
0 \\
1
\end{array}\right]
\end{aligned}
$$

\section{$2 \cdot 1 n$ 次のオブザーバの場合}

系（1）の全状態変数を推定するためのオブザーバ は次式で表わされる6),7).

$$
\begin{aligned}
\dot{\boldsymbol{z}} & =F \boldsymbol{z}+g u+f\left(y-h^{\prime} \boldsymbol{z}\right) \\
& =\left(F-f h^{\prime}\right) \cdot \boldsymbol{z}+g u+f y
\end{aligned}
$$

ここで, $z$ は $n$ 次べクトルである. また $f$ も $n$ 次べク トルでその要素は任意である。いま，

$$
\hat{\boldsymbol{x}}=\boldsymbol{z}(t)=\boldsymbol{x}(t)+\boldsymbol{e}(t)(t \geqq 0)
$$

とおくと，

$$
\boldsymbol{e}(t)=\exp \left[F-f h^{\prime}\right] t \cdot \boldsymbol{e}(0)
$$

である。この $\boldsymbol{e}(t)$ がオブザーバによる推定誤差であ

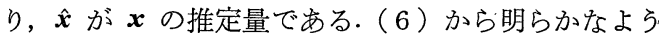
に, $F-f h^{\prime}$ の固有值がすべて負の実部を持てば誤差 $\boldsymbol{e}(t)$ は漸近的に 0 一収束する。 また，F- $f h^{\prime}$ の固有 值は $f$ を指定することによって決まるので, $F-f h^{\prime}$ の固有值が希望の負の実部をもつように $f$ を決めれば よいことになる.

2.2（n-1) 次のオブザーバの場合 オブザーバの方程式は

$$
\dot{\boldsymbol{w}}=E \boldsymbol{w}+d u+l y
$$

ここで,

$E=\left[\begin{array}{ccccc}0 & 0 & \cdots \cdots & 0 & -\alpha_{0} \\ 1 & 0 & \cdots \cdots & 0 & -\alpha_{1} \\ 0 & 1 & \cdots & 0 & -\alpha_{2} \\ \vdots & \vdots & \ddots & \vdots & \vdots \\ \vdots & \vdots & \ddots & \vdots & \vdots \\ 0 & 0 & \cdots & 1 & -\alpha_{n-2}\end{array}\right], \quad d=\left[\begin{array}{c}c_{0}-\alpha_{0} c_{n-1} \\ c_{1}-\alpha_{1} c_{n-1} \\ \vdots \\ \vdots \\ c_{n-2}-\alpha_{n-2} c_{n-1}\end{array}\right]$

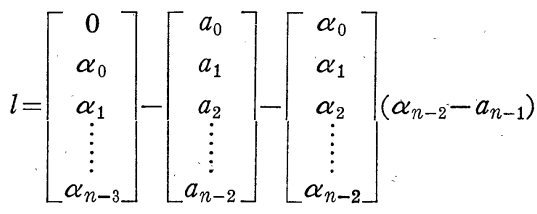

$\alpha_{i}(i=0,1, \cdots, n-2)$ 䚾任意

$\boldsymbol{w}$ は $(n-1)$ 次ベクトル

で与兄られる6),7)。

オブザーバの状態変数 $\boldsymbol{w}$ と系の状態変数 $\boldsymbol{x}$ とは次 式で関係づけられる。

$$
\boldsymbol{w}=T \boldsymbol{x}+\boldsymbol{e}
$$

ここで,

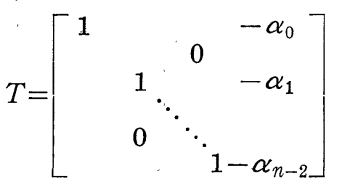

e については,

$$
\dot{\boldsymbol{e}}=E \boldsymbol{e}
$$

が成り立つ，そして，推定量 $\hat{\boldsymbol{x}}$ は次式で与えられる。 


$$
\hat{\boldsymbol{x}}=L_{1} \boldsymbol{w}+L_{2} y
$$

あるいは,

$$
\hat{\boldsymbol{x}}=\boldsymbol{x}+\tilde{\boldsymbol{e}}
$$

ここで,

$$
L_{1}=\left[\begin{array}{c}
\tilde{\boldsymbol{e}} \triangleq L_{1} \boldsymbol{e} \\
I_{n-1} \\
\cdots \cdots \\
0
\end{array}\right], L_{2}=\left[\begin{array}{c}
\alpha_{0} \\
\alpha_{1} \\
\vdots \\
\alpha_{n-2} \\
1
\end{array}\right],
$$

この $\tilde{\boldsymbol{e}}$ が $(n-1)$ 次のオブザーバによる推定誤差で あり, (10)より, $\boldsymbol{e}(t)=\exp E t \cdot \boldsymbol{e}(0)$ なので, この推 定誤差が減少するためにはEの固有值がすべて負の実 部をもたねばならない（8）に特いて $\alpha_{i}$ を適当に 選ぶことにより，Eの固有值を任意に指定することが できる．詳しい議論は参考文献 6)，7）を参照された W.

\section{3. オブザーバの固有值と最適レギュレータの 評価の増分との関係}

評価として，次式を考える。

$$
J=\frac{1}{2} \int_{0}^{\infty}\left[\boldsymbol{x}^{\prime} Q \boldsymbol{x}+r u^{2}\right] d t
$$

ここで，Qは $n \times n$ 実数值対称正定行列であり, $r$ は正数である.

オブザーバを用いて直接測定できない状態変数を推 定し，その推定量金を使ってレギュレータ系を構成す るとき, 状態変数がすべて利用できる場合に比べて評 価（15）には，一般に増分が生じる. J. J. Bongiorno らによれば，その増分は次式で与兄られる3).

$$
\Delta J=\frac{1}{2} \int_{0}^{\infty} \tilde{\boldsymbol{e}}^{\prime} M S M \tilde{\boldsymbol{e}} d t
$$

ここで, $\tilde{\boldsymbol{e}}$ はオブザーバによる推定誤差であり， $M$ は次の代数行列りカッチ方程式の実数值対称正定行列 解である。

$$
[0]=M F+F^{\prime} M-M S M+Q
$$

ただし，

$$
S \triangleq g r^{-1} g^{\prime}
$$

以下では， $n$ 次のオブザーバを用いた場合の $\Delta J$ に ついて論ずるが $(n-1)$ 次の場合も同様に考察できる. $n$ 次の場合, (16) の $\tilde{\boldsymbol{e}}$ に相当するのが (5)よりe であるから，

$$
\Delta J=\frac{1}{2} \cdot \int_{0}^{\infty} \boldsymbol{e}^{\prime} M S M e d t
$$

となる、また， $M S M=\left(g^{\prime} M\right)^{\prime} r^{-1}\left(g^{\prime} M\right)=n \times n$ 定数 行列であり, $\operatorname{rank} M S M=1$ なので $M S M$ の固有值は
0 の $(n-1)$ 重根と $g^{\prime} M$ の各要素の 2 乗和 $\left(=\lambda_{M}\right.$ とする）である. ゆえに，

$$
M S M=U_{1} \Lambda_{M S M} U_{1}^{\prime}=U_{1} \Lambda_{M S M} U_{1}^{-1}
$$

$$
\text { ここで, } \Lambda_{M S M}=\operatorname{diag}\left\{\lambda_{M}, 0, \cdots, 0\right\}
$$

なる直交行列 $U_{1}{ }^{\prime}$ が存在する. かくして (19) は，

$$
\Delta J=\frac{\lambda_{M}}{2} \int_{0}^{\infty}\left(\boldsymbol{\sigma}_{1}^{\prime} U_{1}^{\prime} \boldsymbol{e}\right)^{2} d t
$$

$$
\text { ここで, } \sigma_{1}{ }^{\prime}=[10 \cdots 0]
$$

となる。（21）の計算を実行するには，(6)より $e(t)$ $=\exp \left[F-f h^{\prime}\right] t \cdot \boldsymbol{e}(0)$ だから, $\exp \left[F-f h^{\prime}\right] t$ を求め る必要が生じる。いま,

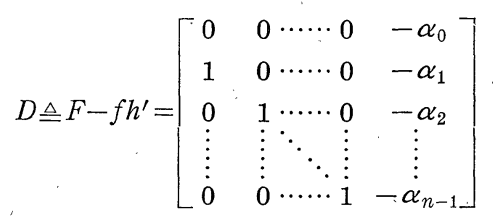

と扣き，固有值は相異なるとし， $\lambda_{1}, \cdots, \lambda_{n}$ と和けば，

$$
\Lambda_{D}=V^{-1} D V
$$

ここで, $\Lambda_{D}=\operatorname{diag}\left\{\lambda_{1}, \lambda_{2}, \cdots \cdots, \lambda_{n}\right\}$ なる正則行列 $V$ が存在し, 次の関係が成立つ ${ }^{8)}$.

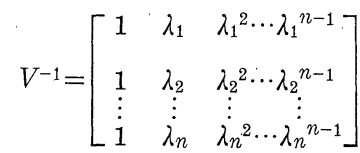

$$
\begin{aligned}
& V=\Theta \cdot \Gamma^{-1} \\
& \Theta=\left[\begin{array}{cccc}
\theta_{n-1}\left(\lambda_{1}\right) & \theta_{n-1}\left(\lambda_{2}\right) & \cdots & \theta_{n-1}\left(\lambda_{n}\right) \\
\vdots & \vdots & & \vdots \\
\theta_{2}\left(\lambda_{1}\right) & \theta_{2}\left(\lambda_{2}\right) & \cdots \cdots & \theta_{2}\left(\dot{\lambda}_{n}\right) \\
\theta_{1}\left(\lambda_{1}\right) & \theta_{1}\left(\lambda_{2}\right) & \cdots \cdots & \theta_{1}\left(\lambda_{n}\right) \\
1 & 1 & \cdots \cdots & 1
\end{array}\right] \\
& \left(\begin{array}{l}
i=1,2, \cdots, n \\
k=0,1, \cdots, n-2
\end{array}\right) \\
& \theta_{k+1}\left(\lambda_{i}\right)=\theta_{k}\left(\lambda_{i}\right) \lambda_{i}+\alpha_{n-1-k} \text { かつ } \theta_{0}\left(\lambda_{i}\right)=1 \\
& \Gamma^{-1}=\left[\begin{array}{ccccc}
\frac{1}{\gamma_{1}} & & & \\
& \frac{1}{r_{2}} & \ddots & \\
& & \ddots & \\
0 & & & \frac{1}{r_{n}}
\end{array}\right] \\
& \gamma_{i}=\left.\frac{d f(\lambda)}{d \lambda}\right|_{\lambda=\lambda_{i}}=\prod_{i \neq j}^{n}\left(\lambda_{i}-\lambda_{j}\right) \text {, } \\
& f(\lambda)=\prod_{i=1}^{n}\left(\lambda-\lambda_{i}\right)=\sum_{i=0}^{n} \alpha_{n-i} \lambda^{n-i}, \alpha_{n}=1
\end{aligned}
$$

これらを用いると，

$$
\exp D t=V \cdot \exp \Lambda_{D} t \cdot V^{-1}
$$

であり，Dの固有值が負の無限遠に近づくときの様子 を知るために， $\lambda_{i}=i \cdot \lambda(i=1, \cdots, n)$ と和くと，(24) は 


$$
V^{-1}=\left[\begin{array}{ccc}
1 & \lambda \cdots & \lambda^{n-1} \\
& & \\
1 & 2 \lambda \cdots(2 \lambda)^{n-1} \\
\vdots & \vdots & \vdots \\
1 & n \lambda \cdots & (n \lambda)^{n-1}
\end{array}\right]
$$

フとなる・そして（26）は，

$$
\Theta=\left[\begin{array}{ccc}
\lambda^{n-1}+\alpha_{n-1} \lambda^{n-2}+\cdots+\alpha_{1} \cdots(n \lambda)^{n-1}+\alpha_{n-1}(n \lambda)^{n-2}+\cdots+\alpha_{1} \\
\vdots & \vdots \\
\lambda^{2}+\alpha_{n-1} \lambda+\alpha_{n-2} \cdots \cdots \cdots \cdots \cdots \cdots(n \lambda)^{2}+\alpha_{n-1}(n \lambda)+\alpha_{n-2} \\
\lambda+\alpha_{n-1} & \cdots \cdots \cdots \cdots \cdots \cdots \cdots \cdots \cdots \cdots \cdots \cdots \cdots \cdots & (n \lambda)+\alpha_{n-1} \\
1 & \cdots \cdots \cdots \cdots \cdots \cdots \cdots & 1
\end{array}\right]
$$

となり，(29）は

$$
\gamma_{i}=\prod_{i \neq j}^{n}\left(\lambda_{i}-\lambda_{j}\right)=\prod_{i \neq j}^{n}(i-j) \lambda^{n-1}(i, j=1,, n)
$$

そなって,

$$
\begin{aligned}
V \simeq\left[\begin{array}{cccc}
0\left(\lambda^{0}\right) & 0\left(\lambda^{0}\right) & \cdots & 0\left(\lambda^{0}\right) \\
0\left(\lambda^{-1}\right) & 0\left(\lambda^{-1}\right) & \cdots & 0\left(\lambda^{-1}\right) \\
\vdots & \vdots & \vdots \\
0\left(\lambda^{-(n-1)}\right) & 0\left(\lambda^{-(n-1)}\right) & \cdots & \left(\lambda^{-(n-1)}\right)
\end{array}\right] \\
0\left(\lambda^{i}\right) \text { は } \lambda^{i} \text { の order を示す. }
\end{aligned}
$$

が得られる。したがって (30) は

$$
\exp D t \simeq\left[\begin{array}{cccc}
0\left(\lambda^{0}\right) & 0\left(\lambda^{1}\right) \cdots \cdots 0\left(\lambda^{n-1}\right) \\
0\left(\lambda^{-1}\right) & 0\left(\lambda^{0}\right) \cdots \cdots 0\left(\lambda^{n-2}\right) \\
\vdots & \vdots & \ddots & \vdots \\
0 & \vdots & \ddots & \vdots \\
0\left(\lambda^{-(n-1)}\right) & 0\left(\lambda^{-\left(\dot{n}^{-2}\right)}\right) \cdots 0\left(\lambda^{0}\right)
\end{array}\right] .
$$

となる。(21) に和ける $\Delta J$ の計算で必要となるのは， $U_{1}{ }^{\prime} \boldsymbol{e}$ の第 1 行目の要素であり, オブザーバの構成の 仕方から, $\boldsymbol{e}(0)$ の要素のらち $\boldsymbol{e}_{n}(0)$ は 0 とすること ができる. $\left(x_{n}\right.$ は出力なので, $z_{n}(0)=y(0)$ とすれば よいから.) そこで, $\boldsymbol{e}(0)=\left[e_{1}(0) \cdots \cdots e_{n-1}(0) 0\right]^{\prime}$ と稀 いて，一般に $e_{n-1}(0) \neq 0$ と考㝋て，

$$
\boldsymbol{e}(t)=\exp D t \cdot \boldsymbol{e}(0) \simeq\left[0\left(\lambda^{n-2}\right) e^{\lambda t} e_{n-1}(0),\right.
$$$$
\left.0\left(\lambda^{n-3}\right) e^{\lambda t} e_{n-1}(0), \cdots 0\left(\lambda^{-1}\right) e^{\lambda t} e_{n-1}(0)\right]^{\prime}
$$

となる.もし， $U_{1}{ }^{\prime}$ の第 1 行が $[0 \cdots 0 x x](x:$ ゼロで ない要素）ならば, $U_{1}^{\prime} \boldsymbol{e} の$ 第 1 行目の order は $0\left(\lambda^{0}\right) e^{\lambda t}$ となり, (21) は,

$$
\begin{aligned}
\Delta J \simeq & \frac{\lambda_{M}}{2} \int_{0}^{\infty} e^{2 \lambda t} e^{2}{ }_{n-1}(0) d t=\frac{\lambda_{M} e^{2}{ }_{n-1}(0)}{-4 \lambda} \rightarrow 0 \\
& (\lambda \rightarrow-\infty)
\end{aligned}
$$

となる.もし， $U_{1}^{\prime}$ の第 1 行が $[0 \cdots 0 x x x]$ ならば, $U_{1}{ }^{\prime} \boldsymbol{e}$ の第 1 行目の order は $0\left(\lambda^{1}\right) e^{\lambda t}$ となり, (21) 纯,

$$
\Delta J \simeq \frac{\lambda_{M} \cdot e^{2}{ }_{n-1}(0)}{-4} \cdot \lambda \rightarrow \infty \quad(\lambda \rightarrow-\infty)
$$

となる.以上のように, $U_{1}{ }^{\prime}$ の構造によって $\Delta J$ の変 化が左右されるが，一般に $U_{1}^{\prime}$ の第 1 行が (36) の 場合のよらに $\left[\begin{array}{lll}0 & \cdots 0 & x x\end{array}\right]$ なることは，ほとんど起こ りえないので (19) の $\Delta J$ はオブザーバの固有値を負 の無限遠に近づけるとき， $n \geqq 3$ ではほとんどの場 合 無限大となる.な特，(n-1）次のオブザーバを用いノ
フた場合には， $y(0)=0$ ならば，ほ汪同様な結論が得 られ， $y(0) \neq 0$ ならば, $n \geqq 2$ のいかなる場合も $\Delta J$ は無限大となることがわかる。

\section{4. オブザーバを考慮した新しい評価}

3.に特いてオブザーバによる推定誤差のために評 価（15）には増分が生じ，しかもオブザーバの固有值 によっては $\Delta J \gg J^{*}\left(J^{*}\right.$ は状態変数がすべて利用でき る場合の最小評価值）の可能性が大であることがわか った.こういら場合には，評価（15）を最小にする制 御則 $u$ を見つけるという問題はあまり意味がない。そ こで， $u=ー k^{\prime} \hat{\boldsymbol{x}}$ を用いるときにこの制御則はどのよ うな 2 次形式評価を最適にしているかを考えることに する.

ここでは, $(n-1)$ 次のオブザーバの場合について 述べるが， $n$ 次の場合についても同様に論ずることが できる. 推定量 $\hat{\boldsymbol{x}}$ は系の状態変数 $\boldsymbol{x}$ とオブザージに よる推定誤差 $\tilde{\boldsymbol{e}}$ との線形結合で表わされるので, 系 の方程式として，（1）と（10）を用いて，

$$
\left[\begin{array}{c}
\dot{\boldsymbol{x}} \\
\dot{\boldsymbol{e}}
\end{array}\right]=\left[\begin{array}{cc}
F & 0 \\
0 & E
\end{array}\right]\left[\begin{array}{l}
\boldsymbol{x} \\
\boldsymbol{e}
\end{array}\right]+\left[\begin{array}{l}
g \\
0
\end{array}\right] u
$$

を考え，評価として

$$
J=\frac{1}{2} \int_{0}^{\infty}\left\{\left[\boldsymbol{x}^{\prime} \boldsymbol{e}^{\prime}\right] Q\left[\begin{array}{l}
\boldsymbol{x} \\
\boldsymbol{e}
\end{array}\right]+r u^{2}\right\} d t
$$

を考光る、ここで，

$$
Q=\left[\begin{array}{ll}
Q_{1} & Q_{2} \\
Q_{2}^{\prime} & Q_{3}
\end{array}\right]>0, \quad r>0
$$

$Q_{1}$ は $n \times n$ 実数値対称正定行列

$Q_{2}$ は $n \times(n-1)$ 実数值行列

$Q_{3}$ は $(n-1) \times(n-1)$ 実数值対称正定行列

（38）は完全可制御ではないが， $(F, g)$ が完全可制 御， $E$ が安定行列とすれば，(39）を最小にする最適 制御則 $u^{*}$ を得ることがでさる（（証明は付録を参照）

$$
\begin{aligned}
& u^{*}=-k^{* \prime}\left[\begin{array}{l}
\boldsymbol{x} \\
\boldsymbol{e}
\end{array}\right] \\
& k^{* \prime}=r^{-1}\left[g^{\prime} 0\right] M
\end{aligned}
$$

ここで, $M$ は次の代数行列リカッチ方程式の実数值対 称正定行列解である. 


$$
\begin{aligned}
& {\left[\begin{array}{l}
0 \\
]
\end{array}\right]=M\left[\begin{array}{cc}
F & 0 \\
0 & E
\end{array}\right]} \\
& +\left[\begin{array}{cc}
F^{\prime} & 0 \\
0 & E^{\prime}
\end{array}\right] M-M\left[\begin{array}{l}
g \\
0
\end{array}\right]\left[r^{-1}\right]\left[g^{\prime 0}\right] M+Q
\end{aligned}
$$
そして

$$
M=\left[\begin{array}{ll}
M_{1} & M_{2} \\
M_{2}^{\prime} & M_{3}
\end{array}\right]
$$

$M_{1}$ は $n \times n$ 実数值対称正定行列

$M_{2}$ は $n \times(n-1)$ 実数值行列

$M_{3}$ は $(n-1) \times(n-1)$ 実数值対称正定行列

と怙き（42）を分割すると，

$$
\begin{aligned}
& {[0]=M_{1} F+F^{\prime} M_{1}-M_{1} g r^{-1} g^{\prime} M_{1}+Q_{1}} \\
& {[0]=M_{2} E+F^{\prime} M_{2}-M_{1} g r^{-1} g^{\prime} M_{2}+Q_{2}} \\
& {[0]=M_{3} E+E^{\prime} M_{3}-M_{2}{ }^{\prime} g r^{-1} g^{\prime} M_{2}+Q_{3}}
\end{aligned}
$$

となる。また（41）は

$$
\begin{aligned}
& u^{*}=-k_{1}{ }^{\prime} \boldsymbol{x}-k_{2}{ }^{\prime} \boldsymbol{e} \\
& k_{1}{ }^{\prime} \triangleq r^{-1} g^{\prime} M_{1}, \quad k_{2} \triangleq r^{-1} g^{\prime} M_{2}
\end{aligned}
$$

となる。 いっぽう, 推定量 $\hat{\boldsymbol{x}}$ は (12), (13) 上り, $\hat{\boldsymbol{x}}=\boldsymbol{x}+L_{1} \boldsymbol{e}$ であり，この $\hat{\boldsymbol{x}}$ を使って制御則をつくる 之,

$$
u=-k^{\prime} \hat{\boldsymbol{x}}=-k^{\prime} \boldsymbol{x}-k^{\prime} L_{1} \boldsymbol{e}
$$

となる. (47) と（48）とが一致するためには，

$k^{\prime}=k_{1}{ }^{\prime}$ かつ $k^{\prime} L_{1}=k_{2}{ }^{\prime}$ すなおち $g^{\prime} M_{1} L_{1}=g^{\prime} M_{2}$

でなければならない（49) が成立するための十分条 件は,

$$
M_{2}=M_{1} L_{1}
$$

であり，必要条件はg の構造によるために明確な形は わからないので，(50）の仮定のもとに議論をすすめ ることにする．(14）の $L_{1}$ の形から，(50)の $M_{2}$ は $M_{1}$ の第 $n$ 列目を削ったものになっている．（50）を （45）へ代入し，（44）を使うと,

$$
Q_{2}=Q_{1} L_{1}+M_{1}\left(F L_{1}-L_{1} E\right)
$$

となり,さらに整理すると。

$$
Q_{2}=Q_{1} L_{1}+M_{1}\left[\begin{array}{cc}
\vdots & \alpha_{0} \\
\vdots & \alpha_{1} \\
0 & \vdots \\
\vdots & \alpha_{n-2} \\
\vdots & 1
\end{array}\right]
$$

を得る。 $Q_{3}$ は $Q>0$ の条件を満たすように決めれば よい. $M_{3}$ は（46）によって $Q_{3}$ と関係づけられて特 り， $Q_{3}$ を決めることによって決まる.

以上のことを簡単な例題で考えてみることにする.

$$
\left\{\begin{array}{l}
\dot{\boldsymbol{x}}=\left[\begin{array}{ll}
0 & 0 \\
1 & 0
\end{array}\right] \boldsymbol{x}+\left[\begin{array}{l}
1 \\
0
\end{array}\right] u \\
y=\left[\begin{array}{ll}
0 & 1
\end{array}\right] \boldsymbol{x}
\end{array}\right.
$$

$$
Q_{1}=\left[\begin{array}{ll}
2 & 0 \\
0 & 1
\end{array}\right], \quad r=1
$$

で記述される系を考光る、いま，オブザーバの固有值 を $-\alpha(\alpha>0)$ とすると,

$$
\dot{e}=-\alpha e
$$

となる．このとき $Q$ と $M$ がどのように求まるかを調 ベる。まず，(44）より $M_{1}$ が求まり，それを(50) へ代入すると $M_{2}$ が求まる. その結果, (52) より $Q_{2}$ 西求まる. そして， $Q_{3}=q$ と特忖ば,

$$
Q=\left[\begin{array}{ccc}
2 & 0 & 2 \alpha+3 \\
0 & 1 & \alpha+2 \\
2 \alpha+3 & \alpha+2 & q
\end{array}\right]
$$

が得られる. 条件 $Q>0$ から，

$$
q>\frac{1}{2}\left(6 \alpha^{2}+20 \alpha+17\right)
$$

となる、また，(46) より $M_{3}$ が求まる。

$$
M_{3}=\frac{1}{2 \alpha}(q-4)>\frac{3}{2} \alpha+5+\frac{9}{4 \alpha}
$$

こうして $M$ は次のように得られる。

$$
M=\left[\begin{array}{ccc}
2 & 1 & 2 \\
1 & 2 & 1 \\
2 & 1 & M_{3}
\end{array}\right]
$$

(58)，(59）より， $\alpha \rightarrow$ 大のを， $q \rightarrow$ 大 $M_{3} \rightarrow$ 大とな り，推定誤差の減衰を速める（いまの場合， $\alpha$ を大き くする）とさには，評価に打いて，eへの重及 $Q_{2}, Q_{3}$ の要素を大きくしなければならないことがわかる，そ して，それに伴って評価の值も大きくなる．この増大 は, オブザーバの推定能力に対応していると考えられ る.

\section{5. 結言}

以上，オブザーバを考虑した新しい評価に対して推 定量を用いた制御則がどのような 2 次形式評価を最適 にしているかについて考察し，十分条件を得た．この 場合, 推定誤差の減衰を速めるときには, 誤差にかか る重みを系の状態変数にかかる重みに比して大きくし なければならない。このことはオブザーバの推定能力, に対応していると考えられ，3. に叔ける増分との関 連で考えるならば，評価に护ける増分は推定誤差によ. る結果であり，誤差の減衰を速めれば速めるほどその 増分は増大するといらことから，最初の評価には含ま れていないオブザーバの推定能力への評価が，暗にそ の増分に対応していると考えることができる。

最後に，有益な助言をいただいた本学助手細江繁幸 氏に深く感謝する。

1) D. G. Luenberger : Observing the State of a Linear 
System, IEEE. Trans. on Military Electronics, MIL-8, 74/78 (1964)

2) D. G. Luenberger:Observers for Multivariable Systems, IEEE Trans. on Automatic Control, AC11-2, 190/197 (1966)

3) J. J. Bongiorno \& D. C. Youla : On Observers in Multi-variable Control Systems, Int. J. Control, 8-3, 221/243 (1968)

4) J. J. Bongiorno \& D. C. Youla : (Correspondence) Discussion of "On Observers in Multi-variable Control Systems", Int. J. Control, 12-1, 183/190 (1970)

5) M.M. Newmann : Specific Optimal Control of the Linear Regulator Using a Dynamical Controller Based on the Minimal-order Luenberger Obser- ver, Int. J. Control, 12-1, 33/48 (1970)

6) Chi-Tsong Chen : Introduction to Linear System Theory, 259/298 Holt, Rinehart and Winston. (1970)

7) B.D. O. Anderson \& J. B. Moore : Linear Optimal Control, 145/191 Prentice-Hall (1971)

8) I.Kaufman : The Inversion of the Vandermonde Matrix and the Transformation to the Jordan Canonical, Form, IEEE Trans. on Automatic Control AC-14-6, 774/777 (1969)

9) R. E. Kalman : When is a Linear Control System. Optimal?, Trans. ASME, J. Basic Engrg., ser. D, 86, 51/60 (1964)

10) R. Bellman : Introduction to Matrix Analysis, 223/ 239 McGraw-Hill (1960)
系の方程式として, 次式 (1) を考光, 評価は（2） を考觉ることにする.

$$
\begin{aligned}
& \dot{\overline{\boldsymbol{x}}}=\overline{\mathrm{F}} \overline{\boldsymbol{x}}+\bar{g} u \\
& J[\overline{\boldsymbol{x}}(t)]=\frac{1}{2} \int_{t}^{\infty}\left[\overline{\boldsymbol{x}}^{\prime} Q \overline{\boldsymbol{x}}+r u^{2}\right] d t
\end{aligned}
$$

ここで

$$
\begin{aligned}
& \overline{\boldsymbol{x}} \triangleq\left[\begin{array}{l}
\boldsymbol{x} \\
\boldsymbol{e}
\end{array}\right], \bar{F} \triangleq\left[\begin{array}{ll}
F & 0 \\
0 & E
\end{array}\right], \bar{g} \triangleq\left[\begin{array}{l}
g \\
0
\end{array}\right] \\
& Q>0, \quad r>0
\end{aligned}
$$

である.いま， $(F, g)$ は完全可制御であり，Eは安定

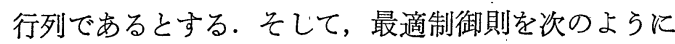
仮定する.

$$
u=-k^{\prime} \overline{\boldsymbol{x}}
$$

ここで, $k$ は $(2 n-1)$ 次のベクトルで要素は未知で ある（4）を（1），(2）へ代入すると,

$$
\begin{aligned}
& \dot{\bar{x}}=\left(\bar{F}-\bar{g} k^{\prime}\right) \overline{\boldsymbol{x}} \\
& J[\overline{\boldsymbol{x}}(t)]=\frac{1}{2} \int_{t}^{\infty} \overline{\boldsymbol{x}}^{\prime}\left(Q+k r k^{\prime}\right) \overline{\boldsymbol{x}} d t
\end{aligned}
$$

が得られ，(6）の時間全微分をとると，

$$
\dot{J}[\overline{\boldsymbol{x}}]=-\frac{1}{2} \overline{\boldsymbol{x}}^{\prime}\left(Q+k r k^{\prime}\right) \overline{\boldsymbol{x}}
$$

となる. $\dot{J}$ は $\overline{\boldsymbol{x}}$ に関して 2 次形式であり, 系 $(5)$ は線形なので, $J$ もまた次の 2 次形式で与兄られると 仮定する。

$$
J[\overline{\boldsymbol{x}}(t)]=\frac{1}{2} \overline{\boldsymbol{x}}^{\prime}(t) M \overline{\boldsymbol{x}}(t)
$$

ここで, $M$ は定数行列であり，初期值 $\overline{\boldsymbol{x}}(0)$ に対する 評価は $J[\bar{x}(0)]$ で与兄られる。（8）の時間微分は，

$$
\dot{j}[\overline{\boldsymbol{x}}]=\frac{1}{2}\left\{\dot{\overline{\boldsymbol{x}}}^{\prime} M \overline{\boldsymbol{x}}+\overline{\boldsymbol{x}}^{\prime} M \dot{\overline{\boldsymbol{x}}}\right\}
$$

\section{録}

となる・（5）を（9）に代入すると

$$
\dot{J}[\overline{\boldsymbol{x}}]=\frac{1}{2} \overline{\boldsymbol{x}}^{\prime}\left\{\left(\bar{F}-\bar{g} k^{\prime}\right)^{\prime} M+M\left(\bar{F}-\bar{g} k^{\prime}\right)\right\} \overline{\boldsymbol{x}}
$$

が得られる.すべての $\boldsymbol{x}$ に対して,（7）と（10）と 夯等しくなるためには，次式が成立していなければな らない.

$$
\left(\bar{F}-\bar{g} k^{\prime}\right)^{\prime} M+M\left(\bar{F}-\bar{g} k^{\prime}\right)=-\left(Q+k r k^{\prime}\right)
$$

（8）で仮定したようと，評価值は $M$ にって決まる. そのMは（11）より $k^{\prime}$ の関数となっている. 評価を

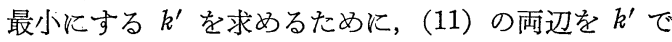
微分すると, $\partial M / \partial k^{\prime}=[0], \partial k^{\prime} \mid \partial k^{\prime}=I$ の性質を使っ $\tau$,

$$
k^{\prime}=r^{-1} \bar{g}^{\prime} M
$$

を得る、これを(11) へ代入すると，

$$
[0]=M \bar{F}+\bar{F}^{\prime} M-M \bar{g} r^{-1} \bar{g}^{\prime} M+Q
$$

となる.ここで,

$$
M=\left[\begin{array}{ll}
M_{1} & M_{2} \\
M_{2}^{\prime} & M_{3}
\end{array}\right], \quad Q=\left[\begin{array}{ll}
Q_{1} & Q_{2} \\
Q_{2}^{\prime} & Q_{3}
\end{array}\right]
$$

$M_{1}, Q_{1}$ は $n \times n$ 実数值対称正定行列

$M_{2}, Q_{2}$ は $n \times(n-1)$ 実数值行列

$M_{3}, Q_{3}$ は $(n-1) \times(n-1)$ 実数值対称正定行列 と执いて，(13）を分割すると，

$$
\begin{aligned}
& {[0]=M_{1} F+F^{\prime} M_{1}-M_{1} g r^{-1} g^{\prime} M_{1}+Q_{1}} \\
& {[0]=M_{2} E+F^{\prime} M_{2}-M_{1} g r^{-1} g^{\prime} M_{2}+Q_{2}} \\
& {[0]=M_{3} E+E^{\prime} M_{3}-M_{2}^{\prime} g r^{-1} g^{\prime} M_{2}+Q_{3}}
\end{aligned}
$$

が得られる. (15) は $M_{2}, M_{3}$ とは無関係であり， し かも $\boldsymbol{e} \equiv \mathbf{0}$ のときのレギュレータ問題と同じになるの で $M_{1}>0$ が求皇る. そして, $F-g r^{-1} g^{\prime} M_{1}$ 快安定行 列になることが知られている ${ }^{92}$. (12) は， 


$$
k^{\prime}=\left[r^{-1} g^{\prime} M_{1}, r^{-1} g^{\prime} M_{2}\right]
$$

となり，最初に仮定した最適制御則（4）は，

$$
u^{*}=-\left[r^{-1} g^{\prime} M_{1}, r^{-1} g^{\prime} M_{2}\right] \overline{\boldsymbol{x}}
$$

となる（5）へ（18）を代入すると，

$$
\dot{\overline{\boldsymbol{x}}}=\left[\begin{array}{cc}
F-g r^{-1} g^{\prime} M_{1} & -g r^{-1} g^{\prime} M_{2} \\
0 & E
\end{array}\right] \overline{\boldsymbol{x}}
$$

となる. $M_{2}$ については，(16）は次のように書き直 すことができる.

$$
[0]=M_{2} E+\left(F-g r^{-1} g^{\prime} M_{1}\right)^{\prime} M_{2}+Q_{2}
$$

そして，(21）の解 $M_{2}$ は次の定理によって存在が保 証さ机る.

\section{<定理 $>$}

$$
A X+X B=C
$$

ここで, $A, B, C, X$ はそれぞれ $m \times m, n \times n, m \times n$, $m \times n$ 定数行列である.

(a) がすべての $C$ 亿対して解をもつための必要十 分条件は $\lambda_{i}+\mu_{j} \neq 0$ である.

ここで, $\lambda_{i}, \mu_{j}$ はそれぞれ $A, B$ の特性根である(証 明は文献 (10) を参照されたい).

(21) 飞対して, (a) 飞执いて;

$$
A=\left(F-g r^{-1} g^{\prime} M_{1}\right)^{\prime}, \quad B=E, C=-Q_{2}
$$

と括けば, $F-g r^{-1} g^{\prime} M_{1}$ と $E$ はとも《安定行列であ ることから，これらの行列の固有值はすべて負の実部 をもち，定理の条件を満たすので解は存在する．また， (20) は漸近安定となる。 このように（19）によって 決をる制御則 $u^{*}$ を用いれば、閉ループ系は漸近安定 となっていることがわかる、(証明終) 